\section{Edycasáa PorilEscrito}

ARTIGO

\section{Editor}

Maria Inês Côrte Vitoria

PUCRS, RS, Brasil

\section{Equipe Editorial}

Pricila Kohls dos Santos PUCRS, RS, Brasil

Marcelo Oliveira da Silva PUCRS, RS, Brasil

Carla Spagnolo

PUCRS, RS, Brasil

Rosa Maria Rigo

PUCRS, RS, Brasil

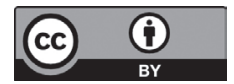

A matéria publicada neste periódico é licenciada sob forma de uma Licença Creative Commons - Atribuição 4.0 Internacional. http://creativecommons.org/licenses/by/4.0/

\title{
Rede de significados para uma educação transformadora: tecendo as concepções da formação docente, filosofia e da psicologia da educação no banco de dados da ANPED nos anos 2009 a 2013 e os referenciais teóricos do cuidar
}

Network of Meanings for a Transformative Education: weaving the conceptions training teachers, philosophy and the psychology of education in the database of ANPED in the years 2009 and 2013, and the referential theoretical of care

Rosália Figueiró Borges ${ }^{\mathrm{a}}$

RESUMO: O cuidado ocorre por uma força que move a capacidade humana de cuidar, evocando esta habilidade em nós e nos outros, ao satisfazer uma resposta a algo ou alguém que importa, atualizando nosso potencial para cuidar. O cuidado, em sua essência, deve ser aprofundado por docentes no que se refere à ontologia, epistemologia, teorias e modelos de cuidar. $\mathrm{O}$ estudo possibilita conhecer a relação entre a educação e o cuidar na perspectiva dos docentes do ensino superior nos processos de educar e ensinar. Dessa forma, infere-se que educador em sua formação docente revela atitudes e comportamentos que possui uma associação direta aos pressupostos teóricos do cuidar. O educador possui um papel de cuidador? Se a educação necessita de uma ambiência e de uma dinâmica social para que haja apreensão do conhecimento por parte do aluno, isso denota a existência de ações de cuidar? De que forma cuidamos dos discentes na educação superior? Trata-se de um estudo exploratório, descritivo, desenvolvido a partir de uma abordagem de pesquisa qualitativa de revisão bibliográfica em bases de dados da ANPED nos anos de 2009 e 2013. O estudo possibilita um exercício reflexivo das ações do educador como sujeito que possui uma bagagem de subjetividade e de uma formação docente permeada de valores de transformação de sua realidade para o ensino. A prática educativa possui uma estreita relação na perspectiva do cuidado e das novas tendências do ensino aprendizado no ensino superior.

Palavras-chaves: Cuidar. Ambiência de ensino. Formação docente.

ABSTRACT: The care is by a force that moves the human capacity to care for, evoking this ability in ourselves and in others, to satisfy a response to something or someone that matters, updating our potential to care. The care, in its

\footnotetext{
a Doutora em Educação. Mestre em Saúde Coletiva. Especialista em Administração Hospitalar Docente do Curso de Enfermagem da UNISINOS/RS. <rosaliafb@yahoo.com.br>.
} 
essence, should be deepened by teachers with regard to ontology, epistemology, theories and models of care. The study allows understanding the relationship between education and the care from the perspective of higher education teachers in the process of educating and training. Thus, it appears that educators in their teacher education reveals attitudes and behaviors that have a direct association with the theoretical assumptions of care. The educator has a caring role? If education needs an environment and a social dynamic so that there is acquisition of knowledge by students, it denotes the existence of caring actions? How we take care of students in higher education? This is an exploratory, descriptive study, developed from a qualitative research approach to literature review on databases ANPED in 2009 and 2013. The study provides a reflective exercise of the educator actions as a subject which has a subjectivity of luggage and a teacher education permeated with transformation values of their reality for teaching. Educational practice has a close relationship with the prospect of care and new trends of teaching learning in higher education.

Keywords: Caring. Ambience of teaching. Teacher education.

$\mathrm{O}$ cuidado é essência do ser. A humanidade encontra-se em uma crise de identidade, visto que tem demonstrado sentimentos e emoções destrutivas da ecologia interna e externa. O ser humano, em suas bases mais profundas e internas, busca compreender a esfera de sua própria essência enquanto "ser humano" e a sua relação com a sociedade e a natureza. O cuidado possui um domínio unificador, pois abrange o holismo (de holos=todo) que engloba não apenas a esfera física, mas a forma como se manifesta o espírito humano. Neste sentido, o cuidado promove um deslocamento de interesse da nossa realidade para a do outro, ou seja, para que "eu me emocione, para que desperte em mim algo que perturbe a minha própria realidade ética, devo encarar a realidade do outro como uma possibilidade para a minha própria realidade". Emerge assim uma outra conotação além do "existencial" no cuidado que é o "relacional", isto é, o eu com o outro e para o outro. Neste sentido, o cuidado passa a ter uma conotação de "interessar-se pelo outro" e isto de certa forma movimenta ambos - "completando-se um no outro" (NODDINGS, 2003, p. 27-28).

Para a idealização do cuidado na esfera da educação é necessário embasá-lo em referenciais ou em teorias de cuidado. De um paradigma positivista, que vigorou durante alguns anos passa-se para um paradigma holístico, humanista ou ecológico correspondendo a uma mudança drástica. Propõe-se uma reflexão sobre os elementos que potencializam o ato de "ensinar" na perspectiva do cuidar. Evidencia-se como justificativa para este recorte, destacar a importância do cuidado para a construção de uma ambiência universitária sendo essa prerrogativa investigativa do estudo. Nesse contexto, optou-se trabalhar com os grupos de trabalhos (GT'S) de formação de professores, filosofia e Psicologia da Educação da ANPED nos anos de 2009 e 2013. O estudo é de caráter exploratório e descritivo com abordagem qualitativa com enfoque em Minayo (2004). Integrou-se três GT'S - formação de professores, Psicologia e Filosofia da Educação. Desta integração resultou em 5 categorias, sendo: Formação Docente (subcategorias: concepção 
sobre formação, desenvolvimento profissional, formação, representações dos docentes, construção da docência, trabalho docente, trabalho educacional, dimensões éticas e estética da formação), Subjetividade (subcategoria: subjetividade no ensino e compreensão do ser), Afetividade e Processo educativo (subcategorias: processo educativo pedagógico, aprendizagem, processo de ensino e práxis). Dos 43 trabalhos publicados em 2009 evidenciou-se: 4 trabalhos que possuíam algumas expressões relacionadas ao cuidar. Dos 45 trabalhos publicados em 2010 apenas 8 expressaram significados e/ou atributos que correspondiam as concepções de cuidar. Nos anos de 2011 e 2013, não evidenciou-se trabalhos que contemplassem atributos do cuidar nos GT'S de formação de professores e de Psicologia. Ressalta-se que no ano de 2012 contatou-se apenas um estudo no grupo de trabalho da Filosofia da Educação.

Esses dados nos permite identificar uma estreita evidência de produção científica de alguns grupos de pesquisa que trabalham na fronteira entre concepções já então conhecidas sobre formação de professores, a filosofia e psicologia da educação e a sua analogia com alguns pressupostos do cuidar. A partir deste instante, é possível delinear algumas possibilidades para a ampliação das concepções que movimenta a formação docente, filosofia e psicologia e sua interlocução no campo do cuidar.

A educação corresponde a uma relação dialógica. Assim sendo, relacionar os fundamentos do cuidar com o processo de educar exige a compreensão dos significados que permeiam o processo de cuidar. A ideia de conhecimento, saber, educação, formação estão diretamente ligados a potencializações da vida. Pressupõe-se que a compreensão dos aspectos subjetivos que movimenta a relação entre professor e aluno estaria atrelada a concepções do cuidar. Portanto, emergem algumas questões sobre como estabelecer a relação dialética e simbiótica entre as possibilidades de desenvolvimento do cuidar no exercício da docência? Quais as possíveis transformações a serem construídas por parte dos professores no processo de ensino e de aprendizagem dentro do cenário teórico do cuidar? Como a ambiência do docente e a prática pedagógica podem influenciar e afetar a aprendizagem dos alunos com o universo do conhecimento? Para responder a essas questões, pretendeu-se estudar a relação entre a educação e o cuidar na perspectiva dos docentes do ensino superior nos processos de educar e ensinar.

\section{Metodologia}

O presente estudo é de revisão bibliográfica e tem caráter exploratório descritivo com abordagem qualitativa, pois visou descrever e desenvolver uma revisão da literatura sobre a relação entre a educação e o cuidar na perspectiva dos docentes do ensino superior nos processos de educar e ensinar. O delineamento metodológico para o presente estudo foi a pesquisa bibliográfica. Conforme define Gil (2002, p. 65) "a pesquisa bibliográfica é desenvolvida a partir de material já elaborado, constituído principalmente de livros e artigos científicos". Descreve o autor que em 
quase todos os estudos é exigido algum tipo de trabalho dessa natureza. Porém, existem pesquisas desenvolvidas "exclusivamente a partir de fontes bibliográficas". Prossegue o autor conceituando que parte dos estudos exploratórios podem ser definidos como pesquisas bibliográficas, assim como certo número de pesquisas desenvolvidas a partir da técnica de análise de conteúdo.

Para a obtenção das informações da pesquisa bibliográfica proposta para esse estudo, foram utilizadas as bases da ANPED que datem de 2009 a 2013. As fontes foram selecionadas a partir dos seguintes descritores: cuidar, ambiência de ensino. A amostra foi constituída por todos os grupos de trabalhos que atenderam ao objetivos propostos e aos seguintes critérios de inclusão. A coleta de dados ocorreu a partir da leitura dos periódicos selecionados e seguiu os seguintes passos conforme Gil (2002):

a) identificação das fontes;

b) localização das fontes e obtenção do material;

c) leitura do material;

d) leitura exploratória de todo material selecionado;

e) leitura seletiva que consiste em uma leitura mais aprofundada das partes que interessam;

f) leitura analítica que tem por finalidade ordenar as informações contidas nas fontes e identificar as ideias chaves do texto.

Após a elaboração das fichas estas foram classificadas conforme seus assuntos de forma que as questões semelhantes fiquem tão próximas quanto possível. As fichas ficaram dispostas segundo a ordem dos assuntos o que facilitou a redação final do trabalho. Foram selecionados materiais que respondiam ao objetivo do estudo e, desenvolveu-se as etapas da pesquisa bibliográfica com base em Gil (2002, p. 84-87), ou seja, formulação do problema, elaboração do plano de trabalho, identificação das fontes, leitura do material, construção lógica do trabalho e redação do texto. Conforme Bardin (1977), a análise de dados ocorreu em três fases: pré-análise; exploração do material e tratamento dos dados, inferência e interpretação.

\section{Categoria Subjetividade da educação: cuidar e educar}

Ao integrar formação, filosofia e psicologia na educação, categorizou-se subjetividade da educação em 2 subcategorias sendo: subjetividade no ensino e compreensão do ser. Neste sentido, destaca-se um olhar na relação dialógica na educação a intersubjetividade, no grupo de estudo sobre filosofia encontrou-se somente um trabalho que menciona, dentro das experiências educativas, que para potencializar a educação é necessário que a subjetividade entre educadores e educados sejam vivenciadas por meio de um palco de infinitos olhares corresponderiam a experiência 
existencial (DANELON, 2010). Silva (2012) em seu estudo sobre a noção de cuidado no âmbito educacional, aponta como uma temática emergente repensar sobre o cuidar se si em uma perspectiva ideal na formação humana.

Em estudo desenvolvido sobre a fenomenologia existencial de Sartre (DANELON, 2010) menciona que o processo educativo deve levar em consideração os projetos individuais de cada pessoa, pois cada um se constitui com singularidade. Além disso, a subjetividade e a intersubjetividade se enfrentam na arena do projeto existencial humano. Desta filosofia de Sartre, remete-se a fundamentação fenomenológica da subjetividade que pode ser tecida com as concepções relacionadas ao "reconhecimento de si", bem como do perceber-se e ser percebido na relação com outro.

Danelon (2010) evidenciou também, que a educação é "pura relação intersubjetiva". Entretanto, nenhum sujeito consegue educar-se sozinho, pois a educação mergulha na cultura do próprio homem. Essa relação inicia na fase da criança que apreende o que o outro lhe apresenta.

Assim sendo, a experiência educativa seja ela escolar-professor/aluno, familiar pais/filho, religiosa-padre/crente, profissional-patrão/empregado ou social- entre colegas que se educam e educadores e educados. Neste sentido, se todo o olhar é intencional carregado de significado, todo o olhar para o outro enquanto sujeito de sua intencionalidade é sinônimo de cuidar, de guardar ações que promovam o outro para a esfera do cuidado com o sujeito.

O cuidado é entendido como um modo de ser, assim sendo sem o cuidado deixa-se de ser humano. Essa é uma fundamentação que se atribui ao tema em análise no que tange ao aspecto filosófico (HEIDEGGER, 2001). Assim sendo, a afirmação de que o cuidado é o que confere a condição de humanidade às pessoas é uma afirmação lógica considerando os pressupostos heideggerianos. Segundo a visão filosófica, o ser humano vive o significado de sua própria vida por meio do cuidado. É atestado ao ser o cuidado o ethos do humano como sendo um modo de ser essencial que configura-se na raiz primeira do ser humano e corresponde a priori: "O cuidado entra na natureza e na constituição do ser humano. O modo-de-ser cuidado revela de maneira concreta como é o ser humano" (BOFF, 2004).

Na pesquisa de Lima (2010) idealizada no grupo de trabalho da filosofia da educação, aborda um ensaio sobre a temática Humanismo, Verdade e Formação uma Ontologia fundamental de Martin Heidegger, abordando a compreensão do ser. O desenvolvimento da capacidade de cuidar é essencial para o desenvolvimento do ser humano (ROACH, 2002).

O cuidado ocorre por uma força que move a capacidade humana de cuidar evocando essa habilidade em nós e nos outros. Assim sendo, satisfaz uma resposta a algo ou alguém que importa, atualizando nosso potencial para o cuidar. Neste sentido, engloba: atos, comportamentos e atitudes. Os atos, realizados no cuidado, variam de acordo com as condições em que ocorrem as situações e com o tipo de relacionamento estabelecido. Existem tipos diferentes ou maneiras diferentes de cuidar as quais variam de intensidade. 
A maneira de cuidar vai ocorrer de acordo com a forma como nos envolvemos com ela a mesma, bem como com o sujeito e isso corresponderia a um motivo de atenção associado ao cuidado (WALDOW, 2006). O processo de cuidar envolve um processo interativo entre cuidadora e ser cuidado, sendo que a primeira tem um papel ativo, pois desenvolve ações acompanhadas de cuidar. O segundo, por sua vez, tem um papel mais passivo e, em função de sua situação, pode tornar-se dependente temporariamente mudando para um papel menos passivo e, contribuir no cuidado, e ser responsável pelo próprio cuidado (WALDOW, 2006).

$\mathrm{Na}$ educação do ensino superior, a internalização do valor e importância do cuidado deveria ser aprofundado no que tange a ontologia, epistemologia, teorias e modelos de cuidar. A transformação, mais evidente, não se resume a conteúdos e sim a atitudes e posturas dos docentes. Dessa forma, há a necessidade de se fazer escolhas de maneira a aceitar ou não a abordagem do cuidado (WALDOW, 2005).

Ao trabalhar a educação na perspectiva do cuidado, busca-se compreender sua rede de significados. Propor uma educação transformadora e inspiradora com base nos pressupostos do cuidar é idealizar ações e comportamentos que movimentam o self do docente. Compreender as diversas multiplicidades que envolvem o processo de ensinoaprendizagem, inclui necessariamente a ideia do outro. Isso envolve as variedades em torno dos saberes, dos conhecimentos, formas de atuação que correspondem a atitudes e comportamentos, a formação deste indivíduo enquanto "ser humano" e sua trajetória da vida acadêmica, subjetividade e ambiência (GARCIA e BORGES, 2010).

Roach (1993) in Waldow (2004), acentua a necessidade do cuidado em uma sociedade cada vez mais violenta e desumanizada. O cuidado é responsivo, significa uma resposta a uma ação em função de algo ou alguém que importa ou merece o interesse do cuidador. O ser humano manifesta comportamentos de cuidar que segundo a autora é considerado "atributos do cuidar", estes representam os 5 Cs: compaixão, competência, confiança, consciência e comprometimento.

Potencializar a ciência do cuidado humano na prática docente consiste em um exercício mais direcionado para novas posturas e re-significados. Noddigns (1984) in Waldow (2004) enfoca o cuidado através de relacionamento considerado a base ontológica e ética. Os elementos essenciais inclui receptividade, reciprocidade e conectividade.

Outro significado importante, não do ponto de vista filosófico, é o desenvolvido por Leinenger (1991) in Waldow (2004) cuja teoria focaliza comportamentos e hábitos culturais no caso de cuidar. O enfoque cultural está associado aos comportamentos de cuidado manifestado em diferentes culturas os quais correspondem ao modo do ser de cada um.

Feldens e Borges (2010), pesquisaram sobre as principais movimentos de troca e produção de vida no grupo de trabalho (GT) 08 - formação de professores e remetem a necessidade de pensar na perspectiva do sujeito do desejo e das relações sociais quando se propõe pensar na relação indivíduo/professor. No cotidiano da prática educacional, 
evidencia-se que os conhecimentos gerados no processo de formação docente é movimentado por desejos. Isso corresponde a forças que nos impulsiona a buscar o que almejamos. Os conhecimentos são gerados através da "filosofia da diferença. Instiga-se a pensar sobre nossa prática, nosso processos de subjetivações, a pensar no "que nos tornamos".

Analisar a movimentação dos saberes e das ações docentes temos que considerar o outro. É preciso entender as questões ligadas a singularidade e às diferenças na formação docente (GARCIA e BORGES, 2010).

As relações do cuidar no âmbito pessoal ou privado, incluem relações genuínas de cuidar ou de cuidado natural. Caracterizam-se por relacionamentos mais íntimos e que em geral abrangem relações de cuidado (interesse, carinho, amor, atenção) com a família e amigos. O cuidado pessoal relativo à dimensão sujeito-self compreende o cuidar de si (WALDOW, 2004).

Neste sentido, pensar em formação docente obrigatoriamente nos remete a redesenhar que nela está inserido o cuidar de si. O docente necessita conhecer a si, rever suas potencialidades, necessidades e limitações. Esse conhecimento favorece: a uma melhor da autoestima, da confiança em si e da vida, bem como a compreensão dos apectos ligados a: cuidar da saúde, do espírito, do intelecto, de tempo, do lazer e assim por diante.

\section{Categoria Formação Docente: relações e interpretações com o cuidar}

Ao se integrar formação, filosofia e psicologia na educação categorizou-se na categoria formação docente em 9 subcategorias, sendo: concepção sobre educação, desenvolvimento profissional, formação, representações dos docentes, construção da docência, trabalho docente, trabalho educacional, dimensões ética e estética da formação.

O texto produzido por Maciel, Isaia e Bolzan (2010) no grupo de trabalho de formação de professores sobre as Trajetórias Formativas de professores Universitários: repercussões da ambiência no desenvolvimento docente, abordam alguns situações merecedoras de destaque. Uma delas estaria ligada a ideia de como se formam os formadores de formadores? Assim, nos remete a pensar em quais as condições subjetivas e objetivas favorecem o desenvolvimento profissional "no" e "para" o exercício da docência na construção de uma ambiência construtiva.

O exercício da docência, exige uma preparação construida ao longo de uma carrreira. Entretanto, quando configura-se a rotina do dia-a-dia, evincia-se uma grande lacuna no domínio do saber e do saber fazer associado ao desconhecimento de como ajudar o estudante a construir seu saber fazer para atuar em uma profissão específica (MACIEL; ISAIA; BOLZAN, 2010). 
As seguintes expressões que podem conduzir à reflexão do cuidar: o ambiente de ensino necessita de um desenvolvimento do profissional necessita passar primeiramente pelas questões objetivas e subjetivas e intersubjetivas que foram citadas no trabalho como forças de ambiência.que repercutem da trajetória formativa.

Estudos de Maciel, Isaia e Bolzan (2010), redirecionam o olhar para a questão de desenvolvimento profissional docente, onde a ambiência envolve as experiências significativas como pessoa e profissional, além disso referem que deve haver meios que propiciem o ingresso para atuar no ensino superior. O mundo interior e exterior do professor estão associadas a ambiência em que exerce a prática docente docente incluindo-se ainda as condições externas de trabalho que são geradoras de transformação e que pode direcionar para o bem estar e autorrealização pessoal.

A ambiência é uma unidade complexa difícil de mensurar, pois envolve aspectos formativos (cognitivosemocionais) e institucionais. A sala de aula corresponde a uma "Ecologia de sala de aula", pois envolve um ambiente interativo no qual os papéis de educador e educando são alternados na vivência dialética. Sala de aula é considerado um ambiente pedagógico onde os sujeitos se reúnem para o aprendizado, bem como há uma continuidade de interações que constituem-se em um microssistema auto-organizativo.

Remetendo-se as questões que fundamentam o cuidado denota-se que as relações entre os seres depende de um ambiente de cuidado. Cumpre ressaltar conforme Waldow (2004), que o cuidado transforma ambientes, hamoniza relações, sensibiliza o humano de cada um e energiza nosso potencial para ajudar os outros a encontrarem os seus potenciais para lidar com as adversidades. Isso pressupõe vencer barreiras, onde se revela uma nova realidade.

Nem todos os profissionais estão preparados e sensibilizados. É necessário respeitar as escolhas e valores diferentes daqueles em que acredita-se. O processo construtivo no desenvolvimento profissional está diretamente ligado a ambiência. O compromisso profissional é resultante da ação reflexiva do professor frente à realidade, em busca de si mesmo, das forças geradoras que levam a docência como profissão. Relacionando-se a questão da ambiência aos significados do cuidado Waldow (2004) aborda-se o significado de cuidar como forma de ser e de se relacionar.

Mayeroff (1971) in Waldow (2004) refere que no contexto existencial o verdadeiro cuidar é aquele em que a relação com o outro promove uma forma de fazer com que este se envolva e ajude o outro a crescer. O desenvolvimento do cuidar na história da humanidade é esplêndido e ímpar, em um primeiro momento atribuiu-se um sentido de sobrevivência , após associa-se ao ser humano "no estar no mundo" em busca da preservação da espécie e de ocupar o seu espaço. Depois com o desenvolvimento da espécie atribui-se o cuidar como uma expressão de interesse e de carinho (WALDOW, 2004).

Nesta segunda fase, é que se percebe o contexto relacional. Considerando que cuidamos não só de pessoas, mas de: coisas, objetos, animais e plantas; as relações de cuidado englobam a dimensão do sujeito-isto ou sujeito coisa. 
No momento em que o ser que cuida, verdadeiramente se envolve, ele interage e responsabiliza-se pelo crescimento e bem estar do outro.

\section{Categoria Afetividade: uma ferramenta didática no processo de ensinar e aprender}

As pesquisas sobre afetividade estão diretamente relacionadas ao campo da psicologia que neste caso, ao integrar-se os três grupos de trabalho como já citado anteriormente ela recai em 3 estudos.

No estudo desenvolvido por Sugahara e Souza (2010), focou-se no contexto dos alunos do curso de pedagogia e licenciatura. Entretanto, a dinâmica da dimensão afetiva percorre em qualquer espaço acadêmico. Evidenciouse atributos do cuidar na perspectiva de alunos em relação a ser professor, sendo: é ter paciência, ter amor ter compreensão. Interligar a visão dos alunos à teoria das representações sociais permitiu compreender a cultura construída da Instituição de Ensino Superior na qual se formaram. Conforme os autores, o professor constrói sua forma de educar a partir do conjunto de situações oferecidas, para garantir sua formação e favorecer seu desempenho. As representações sociais constituem nas formas de conhecimento que são construídas e adquiridas a partir das relações com o outro e com o mundo social, a fim de tornar a realidade compreensível e comum.

Jovchelovitch (2008) in Sugahara e Souza (2010), referem que as disposições no âmbito da subjetividade, isto é das dimensões emocionais e pessoais, fornecem elementos para a construção do espaço intersubjetivo, ou das relações entre Eu, o Outro e o objeto-mundo. Neste sentido, Wallon (2005) in Sugahara e Souza (2010), em sua integração com o meio, existe a inseparabilidade dos domínios afetivos, cognitivo e motor. Já na psicologia da afetividade (CHRISTLIEB, 1994) in Sugahara e Souza (2010), a linguagem do cotidiano melhor traduz os sentimentos do sujeito. Assim sendo, os estudos remetem que o caráter afetivo como: amor, compreensão, diálogo, paciência e respeito estão diretamente associados aos atributos do cuidar citados por (WALDOW, 2004).

A efetividade na Educação está diretamente pontuada na relação professor-aluno. Trata-se de relações de carinho criando um ambiente de bem estar na sala de aula, desvinculando do papel da escola: ensinar os conhecimentos acumulados e legitimados culturalmente pela sociedade (TASSONI e LEITE, 2010).

\section{Categoria Processo Educativo}

Nesta categoria identificou-se dois trabalhos que versavam sobre contribuições de teóricos de Itard e Condilac citados por Cordeiro e Antunes (2009) e o diálogo da filosofia da didatização da educação abordos por DALBOSCO 
(2009). Nestes trabalhos, evidencia-se como foco, a filosofia como campo do saber remetendo-se a reflexões sobre a formação de professores no sentido de no "quê" e no como "ensinar". Partindo das concepções e relatos de Itard, sobre sua experiência com um aluno de 6 anos e de um professor e o momento de conceber "vínculos", ao se relacionar com os pressupostos do processo de cuidar e do processo de educativo esses são muito semelhantes e as diferenças existem no sentido de que ângulo vislumbra-se o resultado que neste caso seria a apreensão do conhecimento e da transformação de um sujeito (aluno) para as conexões da vida e da sociedade.

O ensino centrado no cuidado para Waldow (2005), abvorda que o professor deve ser sensível para perceber as diferenças e adequar o programa ao tipo de método didático e estratégico segundo as características dos alunos. Embora se mostre flexível, aberto ao diálogo e compreensivo, é necessário destacar que, mesmo numa atitude democrática, estabelecendo relações caracterizadas pela honestidade e camaradagem, o professor é o coordenador e facilitador da aprendizagem e a autoridade. A autoridade entendida não com autoritarismo e sim desempenhando um poder sobre significa conhecimento, liderança, e experiência.

Waldow (2005) aborda ainda que o processo de ensino-aprendizagem transcorra de forma saudável e eficiente deve haver: preparo do professor, dedicação nas atividades de ensino, recursos didáticos e ambiente físico.

\section{Categoria Práxis}

Evidenciou-se somente um artigo que teceu algumas abordagens do cuidar. Ferreira (2010), relata que os modelos de formação de professores são fortemente atingidos pela perspectiva pragmatista. Os programas de formação de professores no Brasil valorizam os aspectos técnicos-instrumentais da formação em detrimento da conscientização dos mesmos em função de uma sociedade, em ampla escala, onde ser sobreponha ao ter. Ainda neste mesmo estudo, revelou-se que a filosofia pragmatista ou da prática está presente em diversas esferas da nossa sociedade e possui elementos que influenciam nos modelos de formação continuada de professores. A ideia central é a de o professor deve desencadear um processo de conscientização do aluno.

\section{Considerações finais}

A educação centrada no cuidar é foco de grande atenção de muitos especialistas da área em especial os da área da saúde. Entretanto, a idéia é transpor para um campo maior de atuação, ou seja, todos os educadores de uma forma ou de outra, independente de sua formação devem ser vistos como sujeitos mobilizados a transformar seus espaços acadêmicos. Isso pressupõe uma mudança de "self" no sentido de entender o outro enquanto ser humano. 
Atualmente, há uma grande preocupação com o futuro do planeta, com as questões: ecológicas, a busca da paz e o regate do humano, com a biodiversidade, sustentabilidade, entre outros. Isso leva-nos a pensar necessária em mudanças drásticas de comportamento e de algumas ideologias impostas que mudaram por muito tempo a forma como as pessoas percebiam seus contextos de vida.

$\mathrm{Na}$ educação conforme Waldow (2006) que há trabalhos internacionais que mencionam a necessidade de propor ao ato de educar como meio de desenvolvimento da competência e sensibilidade solidária. Sugere a autora, que o educar como base da iniciativa e solidariedade deve contemplar as dimensões éticas do cuidado. Os quadro pilares da educação mobilizam um pensar e agir de forma a integrar a ideia do cuidado no sentido relacional, principalmente no que tange a descoberta de si mesmo como indivíduo e integrante de uma sociedade.

É um momento ímpar para a educação e, principalmente para o docente, identifica o cuidado como um valor a ser agregado e internalizado. Reconhecendo e explorando seus significados poderá propor um ambiente de cuidado ao discente. Este ambiente, transformado por ações e condutas de um professor/cuidador que demonstra atitudes de cuidar pode resultar em alunos que se tornarão mais confiantes.

Os focos dos estudos, possuem sua essência aos trabalhos desenvolvidos nos cursos de enfermagem. Entretanto, muitas ações dos docentes em outros campos do saber, podem e devem utilizar desses estudos para propor mudanças curriculares em sua área de conhecimento científico. Temos um compromisso acima de tudo social. Conforme Boff (2004) remete-se para um contexto de cuidado com o planeta terra, fundada em várias estratégias que visam desde a construção de uma sociedade sustentável ao respeito pelos seres vivos, da qualidade de vida, da modificação de atitudes e práticas pessoais entre outros.

Portanto, a significação do cuidar é ímpar em nosso meio acadêmico. A transposição de meios para que a ecologia interna vigore de forma a mudar a vida dos seres, nas relações subjetivas e intersubjetivas vislumbrando um compromisso existencial de transformarmos o educando em pessoas amadurecidas, autônomas, sábias e plenamente emanadas de reflexões e inspirações do cuidar.

\section{Referências}

AGUIAR, W. M. de. Superando a dicotimia saber-ação:uma nova proposta para a pesquisa e a formação docente. In: REUNIÃO ANUAL DA ANPED, 32., 2009, Caxambu/MG. Disponível em: <http://www.anped.org.br/32encontro/internas/ver/apresentacao>. Acesso em: 07 abr. 2011.

BARDIN, L. Análise de conteúdo. Lisboa: Edições 70, 1977.

BOFF, L. Saber cuidar: ética do humano - compaixão pela terra. Petrópolis, RJ: Vozes, 2004. 
CORDEIRO, A. F. M.; ANTUNES, M. M. A. M. Relações entre educação aprendizagem e desenvolvimento humano: as contribuições de Jean Marc-Gaspard Itard. In: REUNIÃO ANUAL DA ANPED, 32., 2009, Caxambu/MG. Disponível em: <http://www.anped.org. br/32encontro/internas/ver/apresentacao>. Acesso em: 07 abr. 2011.

DALBOSCO, C. A. Por uma filosofia da educação transformadora. In: REUNIÃO ANUAL DA ANPED, 33., 2010, Caxambu/MG. Disponível em: <http://www.anped.org.br/33encontro/internas/ver/apresentacao>. Acesso em: 07 abr. 2011.

DANELON, D. G. F. Entre experiências e compreensões: cartografias da formação de professores. In: REUNIÃO ANUAL DAANPED, 33., 2010, Caxambu/MG. Disponível em: <http://www.anped.org.br/33encontro/internas/ver/apresentacao>. Acesso em: 07 abr. 2011.

FERREIRA, D. J. Pragmatismo e filosofia da práxis: projetos em disputa na sociedade e na educação docente. In: REUNIÃO ANUAL DA ANPED, 33., 2010, Caxambu/MG. Disponível em: <http://www.anped.org.br/33encontro/internas/ver/apresentacao>. Acesso em: 07 abr. 2011.

GIL, A. C. Métodos e técnicas de pesquisa social. 8. ed. São Paulo: Atlas, 2002.

HEIDEGGER M. Ser e tempo. Petrópolis, RJ: Vozes, 2001.

ISAIA, S. M. de; ROCHA, A. M. da; BOLZAN, D. P. V. Educação Superior: a entrada da docência universitária. In: REUNIÃO ANUAL DA ANPED, 33., 2010, Caxambu/MG. Disponível em: <http://www.anped.org.br/33encontro/internas/ver/apresentacao>. Acesso em: 07 abr. 2011.

LIMA, H. L. A. Humanismo, verdade e formação na ontologia fundamental de Martin Heidegger. In: REUNIÃO ANUAL DA ANPED, 35., 2012, Porto de Galinhas/PE. Disponível em: <http://www.anped.org.br/35encontro/internas/ver/apresentacao>. Acesso em: 07 abr. 2014.

MACIEL, A. M. da R. Trajetórias Formativas de Professores Universitários: repercussão da ambiência no desenvolvimento profissional docente. In: REUNIÃO ANUAL DA ANPED, 32., 2009, Caxambu/MG. Disponível em: <http://www.anped.org.br/32encontro/internas/ ver/apresentacao>. Acesso em: 07 abr. 2011.

MINAYO, M. C. S. O desafio do conhecimento: pesquisa qualitativa em saúde. 2. ed. São Paulo-Rio de Janeiro: Hucitec-Abrasco, 2004.

NODDINGS N. O cuidado - uma abordagem feminina à ética e à educação moral. São Leopoldo, RS: Ed. Unisinos, 2003.

PIVETTA, H. M. F. Reuniões pedagógicas como espaço de reflexão e construção da docência superior: discutindo concepções de formação e docência. In: REUNIÃO ANUAL DA ANPED, 32., 2009, Caxambu/MG. Disponível em: <http://www.anped.org. br/32encontro/internas/ver/apresentacao>. Acesso em: 07 abr. 2011.

ROACH, S. S. The human act of caring: a blueprint for the health professions. Ottawa (CA): Canadian Hospital Association Press, 2002.

SILVA, N. M. A. da S. A reativação noção de cuidado de si a ideia de formação humana: uma recepção tardia de Foucault. In: REUNIÃO ANUAL DA ANPED, 35., 2012, Porto de Galinhas/PE. Disponível em: <http://www.anped.org.br/35encontro/internas/ver/ apresentacao>. Acesso em: 07 abr. 2011. 
SUGAHARA, L. Y.; SOUZA, C. P. de S. A dimensão afetiva nas representações sociais o trabalho docente. In: REUNIÃO ANUAL DA ANPED, 32., 2009, Caxambu/MG. Disponível em: < http://www.anped.org.br/32encontro/internas/ver/apresentacao>. Acesso em 07 abr. 2011.

TASSONI, E. C. M.; LEITE, S. A. da S. A relação de afeto, cognição e práticas pedagógicas. In: REUNIÃO ANUAL DA ANPED, 33., 2010, Caxambu/MG. Disponível em: <http://www.anped.org.br/33encontro/internas/ver/apresentacao>. Acesso em: 07 abr. 2011.

TREVISAN, A. L. Formação ou reificação? A educação entre o mesmo e o outro. In: REUNIÃO ANUAL DA ANPED, 32., 2009, Caxambu/MG. Disponível em: <http://www.anped.org.br/32encontro/internas/ver/apresentacao>. Acesso em: 07 abr. 2011.

WALDOW, V. R. O cuidado na saúde: as relações entre o eu, o outro e os cosmo. Petrópolis, RJ: Vozes, 2004.

WALDOW, V. R. Estratégias de ensino na Enfermagem: o enfoque no cuidado e no pensamento crítico. Petrópolis, RJ: Vozes, 2005.

WALDOW, V. R. Cuidar: expressão humanizadora da enfermagem. Petrópolis, RJ: Vozes, 2006.

\section{Endereço para correspondência:}

Rosália Figueiró Borges

Rua Saldanha Marinho, 345 - Rio Branco

93320-060 Novo Hamburgo, RS, Brasil

<rosaliafb@yahoo.com.br>

Recebido em: julho/2014

Aceito em: dezembro/2014 